\title{
Assessment of the tensile properties of coir, bamboo and jute fibre
}

Nele Defoirdt ${ }^{\mathrm{a}, \mathrm{b}, *}$, Subhankar Biswas ${ }^{\mathrm{a}, \mathrm{c}}$, Linde De Vriese ${ }^{\mathrm{a}}$, Le Quan Ngoc $\operatorname{Tran}^{\mathrm{a}, \mathrm{d}}$, Joris Van

Acker $^{\mathrm{b}}$, Qumrul Ahsan $^{\mathrm{c}}$, Larissa Gorbatikh $^{\mathrm{a}}$, Aart Van Vuure $^{\mathrm{a}}$, Ignaas Verpoest $^{\mathrm{a}}$

${ }^{\mathrm{a}}$ Department of Metallurgy and Materials Engineering, Katholieke Universiteit Leuven, Kasteelpark Arenberg 44 bus 2450, 3001 Heverlee, Belgium

'baboratory of Wood Technology, Ghent University, Coupure Links 653, 9000 Ghent, Belgium

${ }^{\mathrm{C}}$ Department of Materials \& Metallurgical Engineering, Bangladesh University of Engineering and Technology, Dhaka-1000, Bangladesh

${ }^{\mathrm{d} D e p a r t m e n t}$ of Chemical Engineering, Can Tho University, Can Tho City, Vietnam

* Corresponding author. Present address: Laboratory of Wood Technology, Coupure Links 653, 9000 Ghent, Belgium. Tel: +329264 62 $\underline{61}$ 0523, Fax: +32 926462 33. E-mail address:Nele.Defoirdt@UGent.be (N. Defoirdt)

\section{Abstract:}

Natural fibres are studied as alternatives for man-made fibres to reinforce composites while keeping the weight lower. The assessment of the value of some commonly available tropical fibres for the composite industry starts with the determination of the strength, E-modulus and strain to failure through single fibre tensile tests. The mean strength and standard deviation is calculated following the normal and Weibull distribution resulting in the questionable benefit of applying the Weibull distribution. Furthermore, a correction method assesses the real fibre elongation from the measured clamp displacement. This procedure seems to be useful for strong, brittle fibres to produce more reliable results for the E-modulus and strain to failure.

Keywords: B. Mechanical properties, C. Statistical properties/methods, D. Mechanical testing ${ }_{2}$ Natural fibres 


\section{INTRODUCTION}

High performance materials can be made by reinforcing polymers by fibrillar inclusions, like glass or carbon fibres. However, when lightweight products are aimed at, reinforcement can also be achieved by adding natural fibres. The strongest natural fibres, like flax, hemp and bamboo have been the subject of lots of studies. They approach or even exceed the specific mechanical properties of man-made fibres. Because of the environment-friendly concept of natural fibre reinforced composites, researchers explore new uses, where not always the strongest fibres are needed, but rather a fit-for-purpose solution is searched for. This mentality will gain importance as densely populated regions are developing and the need for materials is increasing, while some tropical fibres are available in large quantities. For example coconut fibre or coir is a residual product of the copra (coconut meat or kernel) production, with volumes that exceed the needs for traditional uses like cords, brooms, etc.

To discover the possible value of Vietnamese bamboo and coir fibres and Bangladesh's jute fibres for the composite industry, their properties are assessed in this study. Performing a tensile test is a relatively easy way to determine the mechanical properties of fibres, but because of their small dimensions the use of an extensometer is as yet not possible. Therefore a theoretical correction is worked out to determine the real elongation of the fibre when only the registered displacement of the clamps is available. Furthermore the distribution of the tensile strength is studied: the mean strength and standard deviation following a normal and Weibull distribution is calculated. The Weibull distribution is, mainly for brittle fibres, often suggested when fibres are considered as a chain of linked smaller parts.

\section{EXPERIMENTAL METHODS}

\section{MATERIAL}

Single fibre (i.e. technical fibre which is a fibre constructed of connected elementary fibres) tensile tests have been performed on three tropical fibres: coconut fibre or coir, bamboo fibre and jute fibre. As they are all natural products, their properties not only depend on the plant species, but also on the growing place, surrounding climate, harvest period, extraction method, the date of harvesting and the maturity at harvesting,... 
Coir fibre is extracted out of the husk (mesocarp) of a coconut, the fruit of a coconut palm (Cocos nucifera L.) which is grown extensively in tropical countries. Fibres can be extracted from unripe nuts and are then called 'white coir', while 'brown coir' is extracted after ripening of the coconut. The colour of the fibres depends however also on the coconut palm species, the extraction method and eventually the time between retting and extracting. In this study white coir fibres, supplied by the Can Tho University of Vietnam, were extracted in a purely mechanical way, without any chemical solution. The brown fibres were kindly supplied by the Belgian company TEX-DEM, but the origin and extraction method of these fibres is not known. Bamboo fibres are extracted out of the culms of bamboo plants, family of the grasses. The fibres used in this study are extracted by steam explosion out of plants of the Dendrocalamus membranaceus species, which is a widely spread bamboo plant in Vietnam. These fibres were supplied by the Hanoi University of Technology.

Jute fibres are bast fibres extracted out of plants of the genus Corchorus that grow mainly in warm and moist regions. The fibres of this study were grown in Bangladesh, extracted with a mechanical process and bleached with $\mathrm{H}_{2} \mathrm{O}_{2}$ by the Bangladesh University of Engineering and Technology in Dhaka.

The diameter or cross sectional area of the fibres used for tensile tests is calculated by determining the mass and length of each piece of fibre tested and from the mean density of the fibre species measured by a gas pycnometer. With gas pycnometry one can determine the real density of an amount of fibres as gas penetrates all the (accessible) pores, while using microscopy one measures the diameter including the pores or the apparent density. Furthermore, microscopic measurements become more difficult in the case of fibres with an oval cross section, like the coir fibres in this study. Of course with gas pycnometry the diameter and cross sectional area is assessed by using a mean density, while with microscopy the diameter of every tested fibre can directly be measured. Various samples were measured at different pressures in the pycnometer to get an adequate mean density for every fibre species. For simplicity reasons we have assumed in this paper that each individual fibre has by approximation a constant cross-sectional area over its length. A more detailed study could e.g. 

so.

\section{TENSILE TEST}

The fibres were tested in a mini tensile/compression machine that registers the displacement of the clamps and the force applied on the fibre. To fix the fibres as straight as possible between the clamps, they were glued with a cyanoacrylate-based glue into a paper frame that was cut just before the start of the tensile test (Fig. 1). For coir and bamboo screwed clamps were used, while for jute the clamps were pinches. The clamps were moved at $0.1 \mathrm{~mm} / \mathrm{min}, 1 \mathrm{~mm} / \mathrm{min}$ and $5 \mathrm{~mm} / \mathrm{min}$ for jute, bamboo and coir fibres respectively. A load cell of $200 \mathrm{~N}$ was applied for all fibres, except for the jute fibres where $5 \mathrm{~N}$ was used. Tests were performed on a variety of test lengths to see the influence of this on the tensile properties. For every fibre and every test length $10-15$ fibres were tested, except for white coir where $20-55$ fibres were tested per test length. Samples that broke near the edge of the clamps were excluded from the analysis.

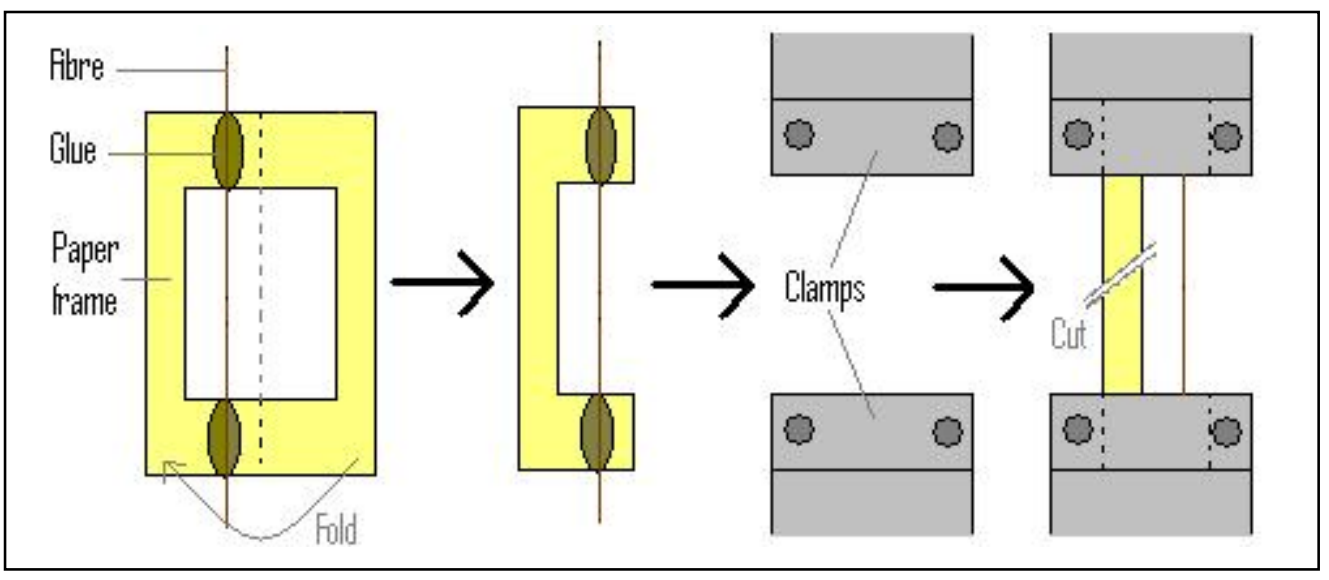

Fig. 1. Use of a paper frame to put the fibre straight between the screwed clamps (analogous for pinching clamps)=

Before gluing the fibres in the paper frame, the mass per length was measured for every used fibre. The cross sectional area, needed to convert the applied loads to stresses, was calculated by dividing the mass per length of each tested fibre by the mean density. 
PROBABILITY OF BREAKING

A plant fibre can be seen as a chain of linked smaller partsconsists of elementary fibre cells connected by the middle lamella, mainly containing pectins. The fibre breaks at the weakest link, which can be e.g. the middle lamella or parts with a smaller diameter. Fig. 2 illustrates that and the longer the fibre, the more chance there is for a weak link where the fibre can break at a certain load [1].

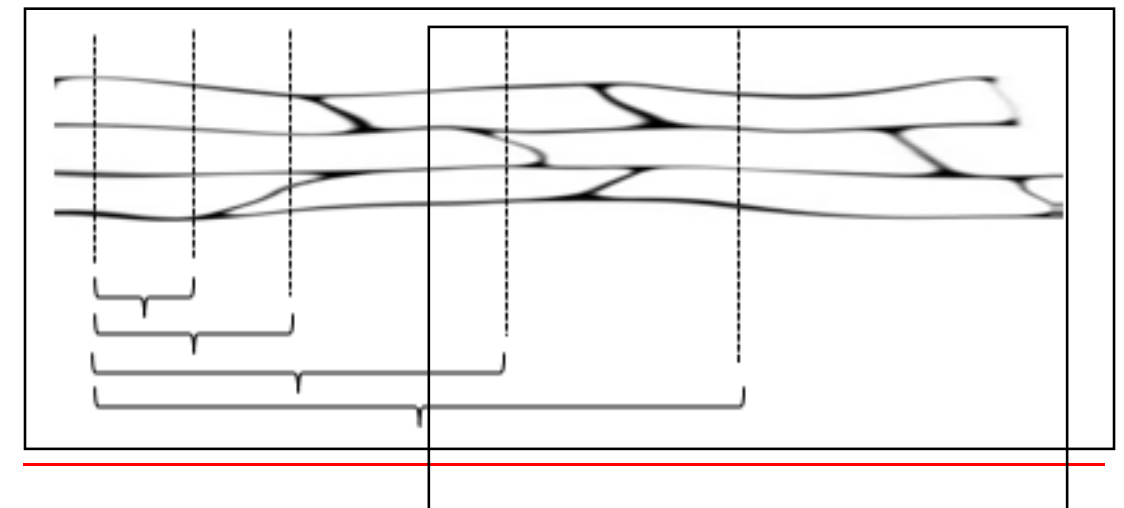

Fig. 2. Illustration of a tech nical fibre consisting of elementary fibre dells. Accolades show
possible clamping distanc\&s

The tensile strength is described through the Weibull distribution by a lot of scientists $[2,3]$. The use of this distribution can be defended if the strength is controlled by the presence of critical flaws and if the material is brittle. The latter means the material has a brittle fracture, thus no significant plastic deformation before it breaks. In this article mean and standard deviation according to the normal and the Weibull distribution are calculated and compared.

The general Weibull distribution is:

$$
F(x ; m, \lambda)=1-e^{\left(-\frac{x}{\lambda}\right)^{m}}
$$

with $\mathrm{m}$ the form factor or shape factor and $\lambda$ the scale factor of the distribution. The expected mean $\mu$ and variance $\sigma^{2}$ of this distribution are:

$$
\mu=\lambda \Gamma\left(1+\frac{1}{m}\right) \text { and } \sigma^{2}=\lambda^{2} \Gamma\left(1+\frac{2}{m}\right)-\mu^{2}
$$


For applying this distribution, a fibre is supposed to have a volume $\mathrm{V}$ that exists of $\mathrm{N}$ parts with volume $\mathrm{V}_{0}\left(\mathrm{~V}=\mathrm{N} . \mathrm{V}_{0}\right) . \mathrm{V}_{0}$ can be calculated by using (literature) values of the mean diameter and length of an elementary fibre cell. The chance that a piece of the fibre breaks at stress $\sigma$ is $F_{1}(\sigma)$, so the chance that it survives that stress is $(1-\mathrm{F} 1(\sigma))$. For a chain of $\mathrm{N}$ parts, the chance of breaking is:

$$
\begin{gathered}
F(\sigma)=1-\left[1-F_{1}(\sigma)\right]^{N} \text { or for big values of } \mathrm{N}: \\
F(\sigma)=1-e^{-N^{*} F_{1}(\sigma)}
\end{gathered}
$$

According to Weibull [4]

$$
F_{1}(\sigma)=\left(\frac{\sigma}{\sigma_{0}}\right)^{m}
$$

where $\sigma_{0}$ represents an average value of the property. This makes the final Weibull distribution:

$$
F=1-e^{-N\left(\frac{\sigma}{\sigma_{0}}\right)^{m}}
$$

With $\mathrm{m}$ the form factor and $\lambda=\sigma_{0} / \mathrm{N}^{\wedge}(1 / \mathrm{m})$ the scale factor. The mean and variance of this distribution are:

$$
\mu=\frac{\sigma_{0}}{N^{\frac{1}{m}}} \Gamma\left(1+\frac{1}{m}\right) \text { and } \sigma^{2}=\left(\frac{\sigma_{0}}{N^{\frac{1}{m}}}\right)^{2} \Gamma\left(1+\frac{2}{m}\right)-\mu^{2}
$$

To determine the Weibull parameters $m$ and $\lambda$, the Weibull distribution can be rewritten as

$$
\ln \left(\ln \left(\frac{1}{1-F}\right)\right)=m \ln \sigma+m \ln \left(\frac{N^{\frac{1}{m}}}{\sigma_{0}}\right)
$$

which has the form $y=m x+b$. By using the median rank approximation for estimating the cumulative probability of failure $F[5]$ :

$$
F=\frac{(\text { rang }-0.3)}{(\max \text { rang }+0.4)}
$$


and making the $(\ln (\ln (1 /(1-F))))$ vs. $\ln (\sigma)$ plot both Weibull parameters, as well as mean and standard deviation can be determined.

\section{CORRECTION METHOD FOR E-MODULUS AND STRAIN TO FAILURE}

With the employed tensile testing device and because no extensometer could be used, the real elongation of the fibres can not be registered. The registered measure is the displacement of the clamps, which means that slippage and test setup compliance are also part of the derived strain [6] and deform the stress-strain curves based on it:

$$
\text { uncorrected strain to failure }=\frac{\Delta l_{\text {total }}}{\text { test length }}=\frac{\Delta l_{\text {fibre }}}{\text { test length }}+\frac{\Delta l_{\text {non fibre }}}{\text { test length }}
$$

with $\Delta \mathrm{I}_{\text {total }}$ the measured displacement of the clamps, $\Delta \mathrm{I}_{\text {fibre }}$ the elongation of the fibre and $\Delta I_{\text {non fibre }}$ the displacement caused by slippage and test setup compliance.

A procedure is now proposed to determine the non-fibre displacement, after which total displacement can be corrected to produce just the fibre displacement. $\Delta \mathrm{I}_{\text {total }}$ is measured and in this procedure considered at a certain stress in the linear part of the stress-strain curve.

$\left(\Delta \mathrm{l}_{\mathrm{fibre}} /\right.$ test length) is calculated by dividing the same chosen stress by the estimated correct $\mathrm{E}$ modulus. This is done by estimating the E-modulus for an infinitely long test length, in other words the extrapolated modulus from an E-modulus versus (1/test length) curve at (1/test length) $=0$. At infinite test length the displacement that is not caused by the elongation of the fibre can be ignored, while at normal test lengths the non-fibre displacement is assumed to be linear with the load put on the fibre:

$$
\frac{\Delta l_{\text {non fibre }}}{\text { test length }}=\frac{\alpha F}{\text { test length }}=\frac{\alpha A \sigma}{\text { test length }}
$$

with $\mathrm{F}$ the load put on the fibre, $\mathrm{A}$ the cross sectional area, $\sigma$ the stress (the same chosen stress as higher mentioned) and $\alpha$ the factor that estimates the influence of slippage and the test setup compliance. So for every tested fibre $\alpha$ can be calculated:

$$
\alpha_{i}=\frac{\Delta l_{\text {total }, i}-\Delta l_{\text {fibre,i }}}{F_{i}} .
$$


In the ideal case this factor should be the same for all fibres of the same plant species and for all measured test lengths. In reality all $\alpha$-values are plotted versus the test length and by a linear regression, an estimation of the $\alpha$-value for each test length can be determined ( $\left.\alpha_{\text {test length }}\right)$, for each type of fibre. With this estimated value for a the corrected strain can be calculated:

$$
\text { corrected strain }=\frac{\Delta l_{\text {fibre, } i}}{\text { test length }}=\frac{\Delta l_{\text {total }, i}}{\text { test length }}-\frac{\alpha_{\text {test length }} F_{i}}{\text { test length }} .
$$

The corrected strain to failure and the E-modulus can finally be determined by drawing the stress versus corrected strain curve. Outliers in tensile strength, E-modulus and strain, before as well as after the correction was executed, were not included for further calculations.

\section{RESULTS}

\section{CHARACTERISATION OF THE MATERIAL}

Mean densities for white coir, brown coir, jute and bamboo are shown in Table 1. The significant difference between the white and brown coir can be caused by a different extraction method and/or by the difference in maturity.

\section{Table 1}

Measured densities of the tested fibres, compared with literature values

\begin{tabular}{llll}
\hline Fibre species & Measured density $\left(\mathrm{g} / \mathrm{cm}^{3}\right)$ & Literature density $\left(\mathrm{g} / \mathrm{cm}^{3}\right)$ & References \\
\hline Coir & White: $1.01 \pm 0.05$ & $1.15-1.25$ & {$[7,8,9]$} \\
& Brown: $1.29 \pm 0.07$ & & \\
Bamboo & $1.38 \pm 0.02$ & $0.6-1.4$ & {$[10,11]$} \\
Jute & $1.39 \pm 0.05$ & $1.3-1.45$ & {$[12,13]$} \\
\hline
\end{tabular}

\section{TENSILE STRENGTH}

Mean tensile strength and its standard deviation employing a normal and a Weibull distribution are plotted in Fig. 2Fig. 3. Means of both distributions are nearly equal and the standard deviation is in a few cases slightly larger in case of the Weibull distribution. 
In Table 2 the Weibull parameters for the fibre species and for the different test lengths are given. A shape factor $(\mathrm{m})$ larger than 2 means that the failure rate increases at an increasing rate as the applied load raises and a shape factor of 3.4 gives a distribution that is similar to a normal distribution. Furthermore the shape factor is an indicator of the variation in the data: the bigger the value for the shape factor $\mathrm{m}$, the smaller the variation in the data. Man-made fibres usually have shape factors between 5 and 15, while for natural fibres that have a larger variation in their properties the values vary mostly between 1 and 6 . Most of the shape factors of this study are in this range, but differ significantly for the various test lengths. The high $\mathrm{m}$ for bamboo with a test length of 15mm corresponds to the deviant data set in Fig. 2Fig. 3 and the higher $\mathrm{m}$ values for brown coir fibres with short test lengths correspond to the datasets that are further away from the trend line.
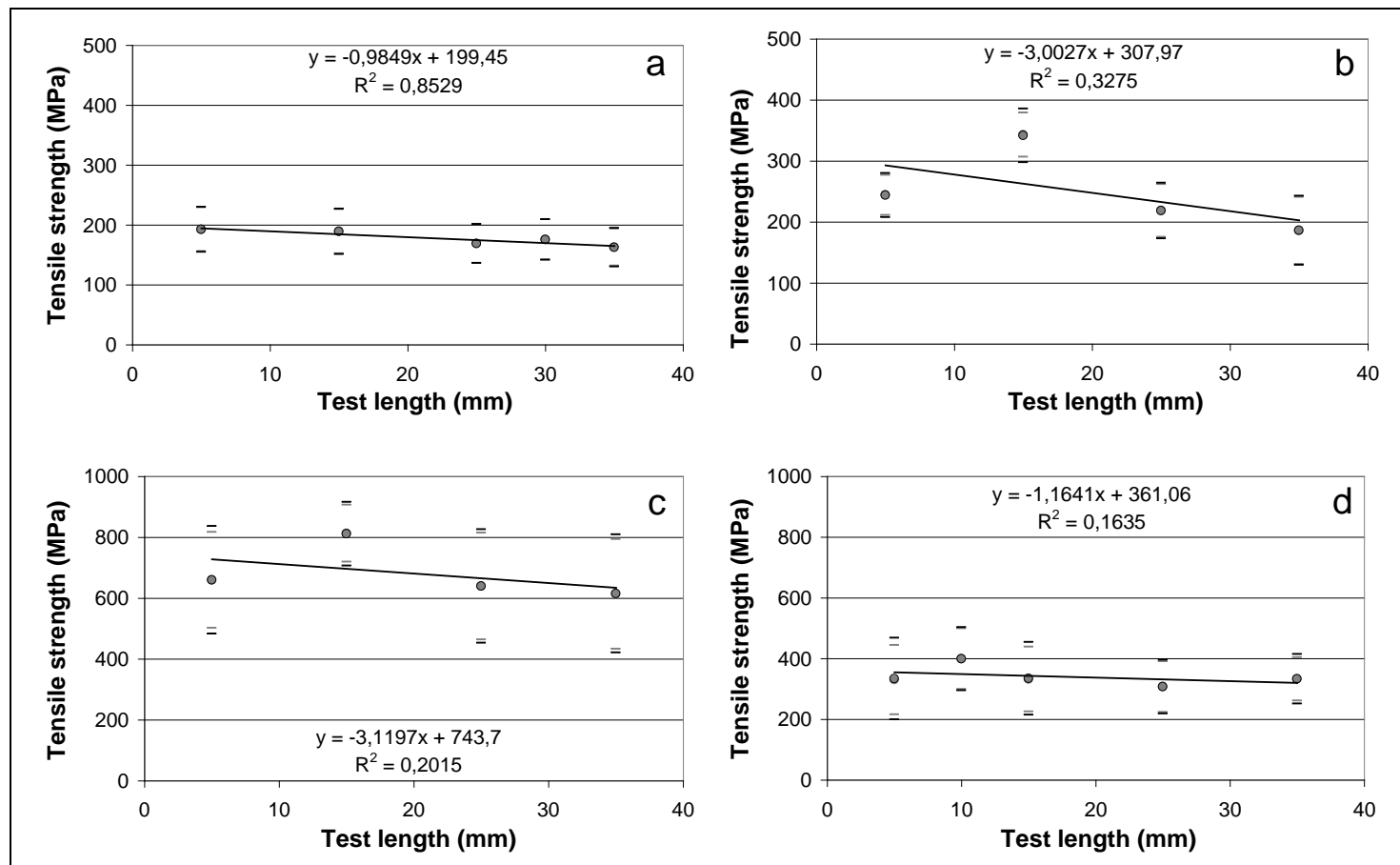

Fig. 2Fig. 3. Tensile strength in function of the test length according to a normal $(\odot$, standard deviation: - ) and Weibull (O, standard deviation: - ) distribution for (a) white coir, (b) brown coir, (c) bamboo and (d) jute fibres; both distributions closely coincide- 


\section{Table 2}

Weibull parameters calculated on the strength data of different test lengths

\begin{tabular}{|c|c|c|c|c|c|}
\hline $\begin{array}{l}\text { Test length } \\
(\mathrm{mm})\end{array}$ & Parameter & White coir & Brown coir & Bamboo & Jute \\
\hline 5 & $\mathrm{~m}(/)$ & 6.0 & 8.0 & 4.2 & 2.7 \\
\hline 10 & & I & I & I & 4.3 \\
\hline 15 & & 5.8 & 9.3 & 9.3 & 3.0 \\
\hline 25 & & 6.0 & 5.5 & 3.8 & 3.9 \\
\hline 30 & & 6.0 & I & I & I \\
\hline 35 & & 5.8 & 3.7 & 3.5 & 4.6 \\
\hline 5 & $\underline{\lambda}=\sigma_{0} \underline{ } / \mathrm{N}^{\wedge}(1 / \mathrm{m})$ & $738 \underline{207}$ & $642 \underline{259}$ & $3408 \underline{726}$ & $1080 \underline{375}$ \\
\hline 10 & $\sigma_{\theta^{-}}(\mathrm{MPa})$ & I & I & l & $927 \underline{438}$ \\
\hline 15 & & $783 \underline{204}$ & $822 \underline{360}$ & $1961 \underline{855}$ & $1270 \underline{374}$ \\
\hline 25 & & $757 \underline{182}$ & $1083 \underline{237}$ & $5867 \underline{707}$ & $954 \underline{339}$ \\
\hline 30 & & $789 \underline{189}$ & I & I & I \\
\hline 35 & & $747 \underline{175}$ & 2456206 & $7199 \underline{683}$ & $931 \underline{364}$ \\
\hline
\end{tabular}

Furthermore in Fig. 3 one can see that For all fibre species the strength decreases as the test length increases because, as reported earlier, with larger test lengths there are more flaws in the fibres that make the chance of failure larger. It is remarkable that the measured strength with a $5 \mathrm{~mm}$ test length is in three of the four cases smaller than that of the $15 \mathrm{~mm}$ test length and the following decreasing trend. A $5 \mathrm{~mm}$ test length may be too much influenced by side effects (e.g. from the clamps).

The tensile strength of coir fibres is mainly situated between the literature values (Table 3); only the results of the $15 \mathrm{~mm}$ test length of brown coir are higher. The results for jute are rather low compared to the strength range found in literature, while the measured bamboo fibres seem to have a relatively high tensile strength in spite of the damaging steam explosion extraction method. 
A measure for the defect density in the fibres can be calculated as the slope of the plot of the tensile strength vs. the test length [1]. In this study the defect density would be bamboo>brown coir $>$ jute $>$ white coir which means the steam explosion extraction of the bamboo fibres causes a lot of defects, while the mechanical extraction of white coir causes least defects.

\section{Table 3}

Measured tensile strength values (normal distribution) compared to literature values

\begin{tabular}{|c|c|c|c|}
\hline Fibre species & $\begin{array}{l}\text { Measured tensile strength }{ }^{a} \\
(\mathrm{MPa})\end{array}$ & $\begin{array}{l}\text { Literature tensile strength } \\
\text { Range (MPa) }\end{array}$ & References \\
\hline White coir & $162 \pm 32-192 \pm 37$ & $120-304$ & {$[9,14]$} \\
\hline Brown coir & $186 \pm 55-343 \pm 36$ & & \\
\hline Bamboo & $639 \pm 175-813 \pm 94$ & $140-800$ & {$[11,13]$} \\
\hline Jute & $307 \pm 84-399 \pm 100$ & $393-1000$ & {$[2,15]$} \\
\hline
\end{tabular}

${ }^{\mathrm{a}}$ Weakest test length - strongest test length

\section{E-MODULUS}

Measured and corrected (see further) E-moduli are presented in function of the used test lengths in Fig. 3Fig. 4. The measured modulus is clearly depending on the used test length which means that side effects (slippage, test setup compliance) influence the moduli. The uncorrected extrapolated E-moduli for infinitely long fibres are 3.39 GPa, 4.16 GPa, 33.90 GPa and 24.70 GPa for respectively white coir fibre, brown coir fibre, bamboo fibre and jute fibre. These values are used in the correction method. 

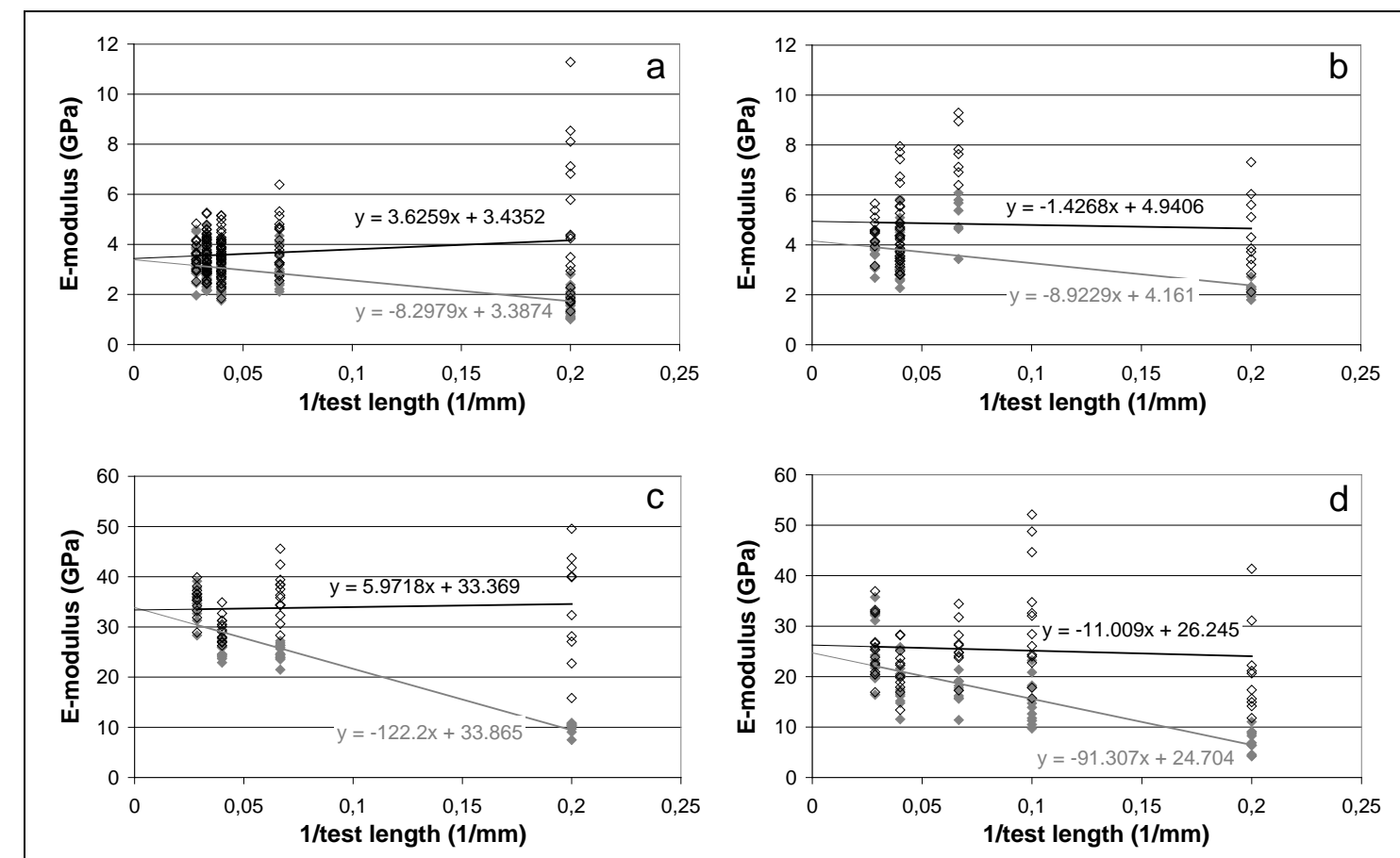

Fig. 3Fig. 4. Measured $(\diamond)$ and corrected $(\diamond)$ E-moduli in function of (1/test length) for (a) white coir, (b) brown coir, (c) bamboo and (d) jute fibres:

Alpha values (formula 14) were calculated for all tested fibres and are depicted in Fig. $4 \underline{\text { Fig. } 5}$. The figures indicate a slight dependence on the test length. Except for brown coir, alpha decreases with increasing test length. Furthermore alpha seems to be inversely proportional to the diameter (or clamped surface area) of the four tested plant fibres (Fig. 5Fig. 6). The values for white and brown coir have the same order of magnitude, but while the mean diameter from tested white coir fibres is a bit smaller than that of the brown fibres, the alpha value for white fibres is slightly larger. The alpha values for the thicker bamboo fibres were 10 times smaller. The alpha values of jute show more scatter which can be attributed to the different clamping system, but generally the thinnest fibres of this study have the largest mean alpha value.

There is a suggestion that the alpha value is largely caused by phenomena like slippage. One could expect that the test-set-up compliance would be a constant. With all the sources of compliance basically loaded in series (so individual compliances can be added), considering the values for bamboo, it seems the test-set-up compliance is very small. So, the main effect 
controlling alpha seems to be slippage. Then, it seems thicker fibres are less prone to slippage in the clamps. It is plausible that a larger contact area will help to prevent slippage. Why slippage would furthermore decrease with test length remains as yet unclear. All this definitely means that alpha would not be a constant and therefore we have assumed it to be material and test length dependent.

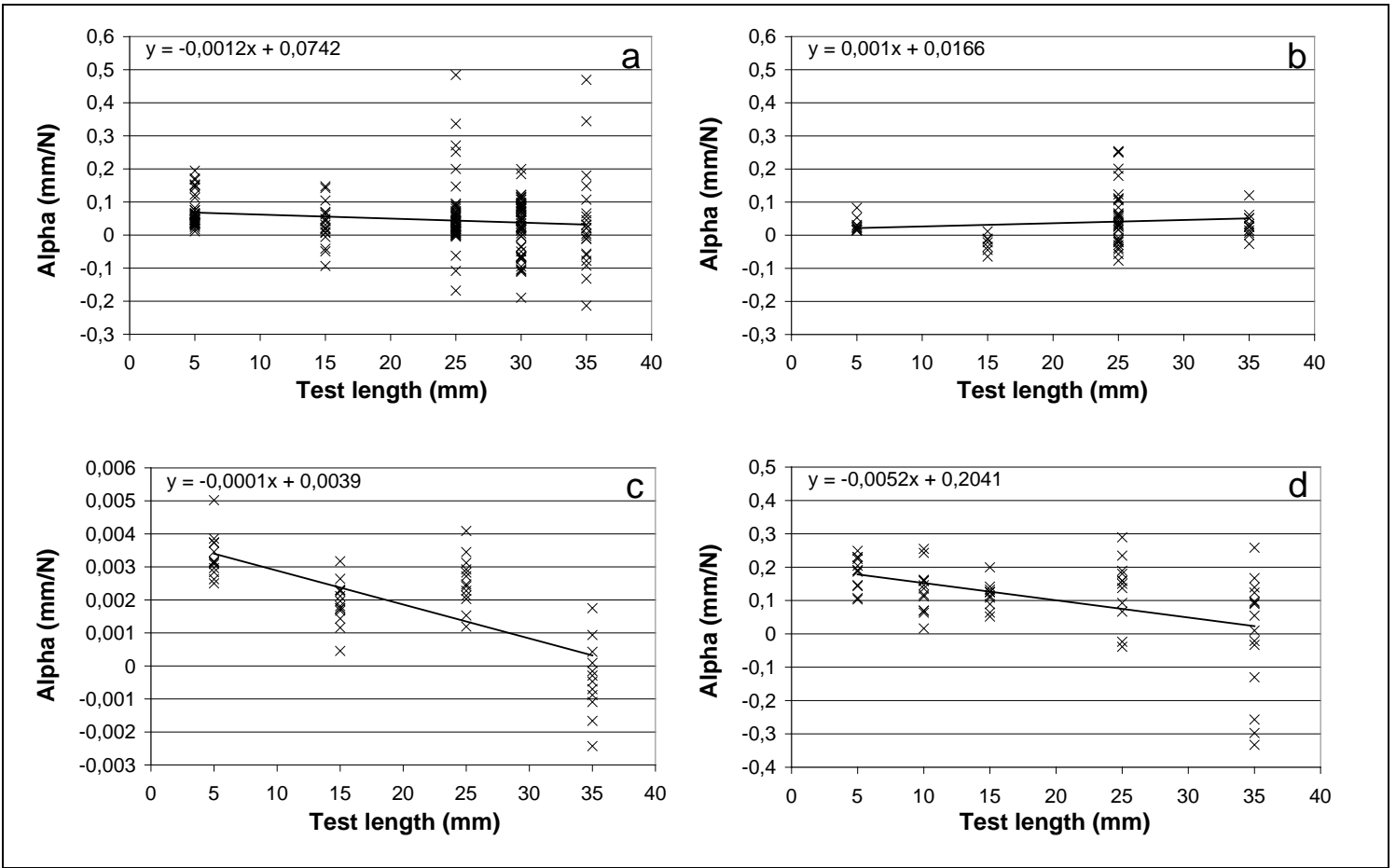

Fig. 4Fig. 5. Alpha values in function of the test length for (a) white coir, (b) brown coir, (c) bamboo and (d) jute fibres-

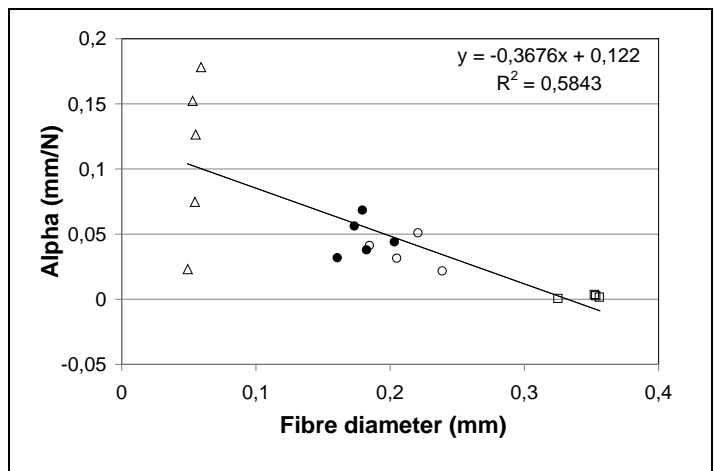

Fig. 5Fig. 6. Alpha related to the fibre diameter for (๑) white coir, (0) brown coir, (ם) bamboo and $(\Delta)$ jute fibres (alpha values and mean diameter for every test length are shown)= 
The estimated alpha values for each test length, read from the linear regression lines, were used for correcting the measured strains. Corrections of the E-modulus (Fig. 3Fig. 4) are larger at shorter test lengths, which means that for shorter test lengths the strain is determined more by slippage in the clamps and test setup compliance (as expected). The figure of brown coir fibres shows that systematic deviations are not eliminated by the correction method as results for the $15 \mathrm{~mm}$ test length stay above the regression line after correcting them.

For jute the results are situated in the range that was found in literature (Table 4), the modulus of bamboo is slightly higher. The modulus of white coir is slightly lower than usually reported. However, Silva et al. [16] also reported lower values and attributed this to the oval cross section that contrasts with lots of reported coir cross sections.

\section{Table 4}

Measured and corrected E-moduli of infinitely long fibres compared to literature values

\begin{tabular}{lllll}
\hline Fibre & Measured & Corrected & Literature & References \\
species & $\begin{array}{l}\text { E-modulus } \\
(\mathrm{GPa})^{\mathrm{a}}\end{array}$ & $\begin{array}{l}\text { E-modulus } \\
(\mathrm{GPa})\end{array}$ & $\begin{array}{l}\text { E-modulus } \\
(\mathrm{GPa})\end{array}$ & \\
& 3.39 & 3.44 & $4-6$ & {$[12,16]$} \\
White coir & 4.34 & $4-6$ & \\
Brown coir & 4.16 & 4.94 & $11-30$ & {$[11,13]$} \\
Bamboo & 33.87 & 33.37 & $13-54$ & {$[14,15]$} \\
Jute & 24.70 & 26.25 & & \\
\hline
\end{tabular}

\section{STRAIN TO FAILURE}

After correction, the strain to failure stays dependent on the test length (Figure 6Fig. 7), which is logically linked to the breaking possibility theory. The longer the fibres, the more weaknesses and the earlier (with low strain to failure) they break. The corrections in the strain to failure are relatively larger for bamboo and jute fibre than for the coir fibres (because they are stiffer). The maximum strain to failure of coir fibres, measured with a $5 \mathrm{~mm}$ test length, exceeds the literature values (Table 5). The values measured at other test lengths stay between the referred 
values. The corrected measurements of jute fibres are situated within the range in literature, but the corrected values for bamboo were significantly higher than the ones found in literature.

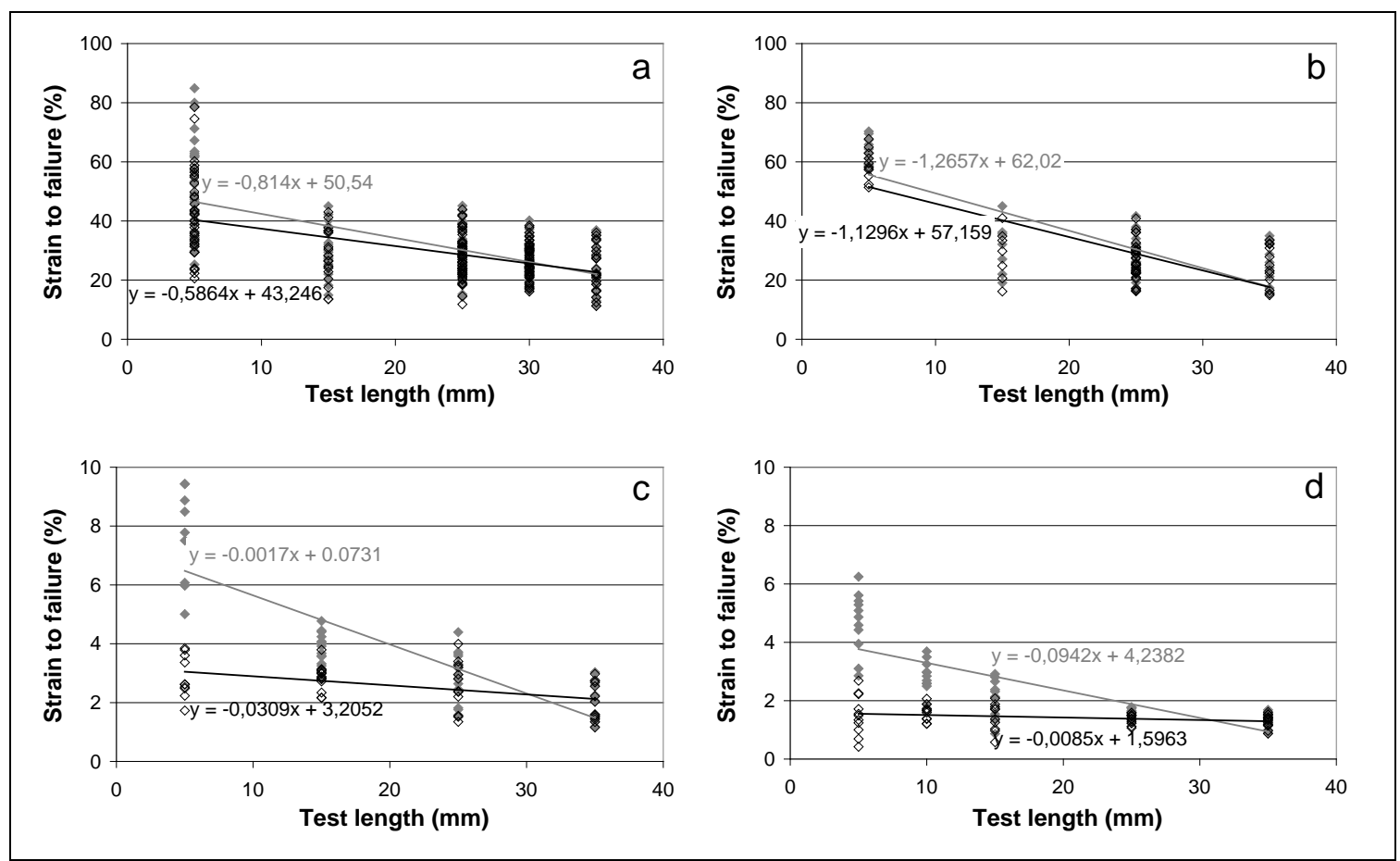

Fig.6Fig. 7. MeasL ed ( ) and corrected ( ) strain to failure in function of the test length for

(a) white coir, (b) brown coir, (c) bamboo and (d) jute fibres- 


\section{Table 5}

Measured and corrected strain to failure compared to literature values

\begin{tabular}{|c|c|c|c|c|c|}
\hline $\begin{array}{l}\text { Fibres } \\
\text { species }\end{array}$ & $\begin{array}{l}\text { Measured } \\
\text { diameter } \\
(\mu \mathrm{m})\end{array}$ & $\begin{array}{l}\text { Measured strain } \\
\text { to failure }{ }^{a} \\
(\%)\end{array}$ & $\begin{array}{l}\text { Corrected strain } \\
\text { to failure }{ }^{a} \\
(\%)\end{array}$ & $\begin{array}{l}\text { Literature } \\
\text { strain to } \\
\text { failure } \\
\text { (\%) }\end{array}$ & References \\
\hline White coir & $198 \pm 75$ & $\begin{array}{r}24.2 \pm 7.7- \\
49.6 \pm 15.0\end{array}$ & $\begin{array}{r}26.1 \pm 5.6- \\
42.4 \pm 14.0\end{array}$ & $15-44$ & {$[9,17]$} \\
\hline Brown coir & $203 \pm 52$ & $\begin{aligned} 25.5 \pm 7.1- \\
63.8 \pm 4.2\end{aligned}$ & $\begin{array}{r}24.5 \pm 6.8- \\
59.0 \pm 5.0\end{array}$ & $15-44$ & {$[9,17]$} \\
\hline Bamboo & $366 \pm 74$ & $\begin{array}{l}2.0 \pm 0.6- \\
7.5 \pm 1.6\end{array}$ & $\begin{array}{l}2.0 \pm 0.6- \\
2.9 \pm 0.7\end{array}$ & 1.3 & [10] \\
\hline Jute & $54 \pm 10$ & $\begin{array}{l}1.4 \pm 0.2- \\
4.7 \pm 1.0\end{array}$ & $\begin{array}{r}1.4 \pm 0.2- \\
1.6 \pm 0.3\end{array}$ & $1.16-2.5$ & {$[2,15]$} \\
\hline
\end{tabular}

${ }^{\mathrm{a}}$ Weakest test length - strongest test length

\section{DISCUSSION}

As the Weibull distribution is normally used for brittle fibres, its application on data of coir fibre is in fact not justified because in the stress-strain curves plastic deformation is clearly noted. However it was considered interesting to compare the theory on coir fibres and the brittle bamboo and jute fibres. Because the mean and standard deviation according to a normal and a Weibull distribution turn out to be nearly equal, the benefit of applying a Weibull distribution to describe fibre strength is questionable. Zafeiropoulos \& Baillie [3] determined mean and standard deviation according to those two distributions for results of tensile tests on flax fibres and also come to the same conclusion. They also remark that the Weibull parameters should be the same for different test lengths, which is not the case in their and this study. Therefore the applicability of the Weibull statistics for fibre strength description should be further examined. 
As noted before, the decrease in tensile strength and strain to failure with increasing test length is explained by the larger chance for weak links in longer fibre parts. Tomczak et al. [1] attribute the increase of the E-modulus with increasing test length to the multicellular structure and structural non-homogeneity of the fibres. It seems however, as also concluded by Joffe et al. [6], that this phenomenon is caused by slippage in the clamps and test setup compliance. Also, most researchers only test one test length and don't mention the use of extensometers or how the actual fibre elongation is determined. Van Dam et al. [9] use the displacement of the clamps to calculate the strain without any correction.

In this study a correction method for slippage and test setup compliance was developed. The strain is calculated based on the corrected fibre elongation, not on the clamps' displacement. In the case of the coir fibres the strain to failure is still depending on the test length, which is logical. The values vary with a factor of 1.62 (white coir) to 2.41 (brown coir). However, this dependence is very small for the bamboo (factor 1.45) and jute fibres (factor 1.14). This might suggest that the density of mayor defects in bamboo and jute fibres is much higher than in coir fibres, and hence that even at small fibre lengths sufficiently high probability for large defects is present.

Concerning the E-moduli, the uncorrected slopes of E vs. test length curves were $0.03-0.05$ for coir, 0.49 for jute and 0.72 for bamboo while the corrected ones decreased to the very small values of $-0.02,-0.03$ and -0.04 indicating that the E-modulus is almost insensitive to the fibre length, as it should be. This means the correction is bigger for jute and bamboo than for the coir fibres.

Concluding, the effect of slippage and the test set up compliance seems to be larger in case of strong, brittle fibres and needs to be corrected in these cases. On the other hand these effects are smaller in case of coir, where probably plastic deformation starts before significant slip and test set up compliance can influence the results.

The difference in mechanical properties of the tested fibre species is linked to their function in nature, which is translated into their physical, chemical and morphological properties [12]. The tensile strength is for example mainly provided by the cellulose content and the microfibrillar 
angle is proportional to the strain to failure. The modulus of elasticity is proportional to the cellulose content and inversely proportional to the microfibrillar angle.

Coir fibres have to prevent the nut from breaking when it falls out of the tree whereby the strength of the fibres is not as important as the energy absorption at impact. Coir fibres have a low cellulose content $(32-53 \%)$ and a big microfibrillar angle $\left(30-49^{\circ}\right)[1,16]$ what makes that these fibres have a low strength, a low modulus of elasticity and a high strain to failure (leading to a higher impact energy at failure).

The fibres in the bamboo plant have a supporting function as they have to keep the stems straight. Bamboo fibres exist of a series of many thin and thick cell wall layers with varying microfibrillar angles and have a cellulose content of $26-61 \%$ [10]. Unfortunately the steam explosion method is a hard method which causes a lot of damage to the fibres.

Jute fibres also need to keep the stalk of the plant upright. Jute fibres have a cellulose content of $61-71,5 \%$ and a microfibrillar angle of only $8^{\circ}[15]$, which make it a strong fibre with a rather high modulus of elasticity and a low strain to failure.

Jute and bamboo fibres can be true reinforcing fibres in light weight high performance composites due to their high tensile strength and E-modulus. Still, bamboo fibres tested in this research are two times stronger and one third stiffer than the jute fibres. The function of coir fibres will be different as they can not provide a lot of strength and stiffness to a composite, but they can potentially make composites tough due to the high strain to failure. Furthermore these fibres can be used in hybrid composite materials, where they can improve the impregnation of finer natural fibres (like flax and hemp, resp. diameter: 32-60 $\mu \mathrm{m}$ and 59-11 $\mu \mathrm{m}$ [14]) because the relatively large fibre diameter can make the stack of fine natural fibres more open to the resins.

\section{CONCLUSION}

When the composite industry looks for light reinforcements for their products, they have the option to choose natural fibres. The potential functions of the tested tropical fibres that are commonly available depend on their mechanical properties. Bamboo and jute can give strength 
to composites, while coir can ameliorate the toughness and improve the impregnation of small diameter fibres when they are mixed in hybrid composites. The correction method for single fibre tensile testing as presented in this paper has a significant effect on the results for bamboo and jute fibres, but the necessity for and the influence on the coir fibre results is small. Finally, the benefit of using the Weibull distribution to study the strength of natural fibres is questionable as the mean and standard deviation according to this distribution are nearly equal to those calculated according to the normal distribution and because the Weibull parameters vary with the test length.

\section{ACKNOWLEDGEMENTS}

We would like to thank the Belgian Federal Science Policy Office (BelSPO) for financing this project and the Vietnamese Ministry of Science and Technology (MOST) for its support.

\section{REFERENCES}

[1] Tomczak F, Sydenstricker THD, Satyanarayana KG. Studies on lignocellulosic fibres of Brazil. Part II: Morphology and properties of Brazilian coconut fibres. Compos Part A-Appl S 2007;38(7):1710-1721.

[2] Tripathy SS, Landro LD, Fontanelli D, Marchetti A, Levita G. Mechanical properties of jute fibers and interfacial strength with an epoxy resin. J Appl Polym Sci 2000;75(13):15851596.

[3] Zafeiropoulos NE, Baillie CA. A study of the effect of surface treatments on the tensile strength of flax fibres: Part II. Application of Weibull statistics. Compos Part A-Appl S 2007;38(2):629-638.

[4] Weibull W. A statistical distribution function of wide application. J Appl Mech 1951;18:293297.

[5] Fothergill JC. Estimating the cumulative probability of failure data points to be plotted on Weibull and other probability paper. IEEE T Electr Insul 1990;25(3):489-492.

[6] Joffe R, Andersons J, Wallström L. Strength and adhesion characteristics of elementary flax fibres with different surface treatment. Compos Part A-Appl S 2003;34(7):603-612. 
[7] Geethamma VG, Mathew KT, Lakshminarayanan R, Thomas S. Composite of short coir fibres and natural rubber: effect of chemical modification, loading and orientation of fibre. Polymer 1998;39(6-7):1483-1491.

[8] Wambua P, Ivens J, Verpoest I. Natural fibres: can they replace glass in fibre reinforced plastics? Comp Sci Technol 2003;63(9):1259-1264.

[9] Van Dam JEG, van den Oever MJA, Keijsers ERP, van der Putten JC, Anayron C, Josol F, Peralta A. Process for production of high density/high performance binderless boards from whole coconut husk. Part 2: Coconut husk morphology, composition and properties. Ind Crop Prod 2006;24(2):96-104.

[10] Alann A. Fibres for strengthening of timber structures. PhD Thesis, Luleå University, Luleå, 2006.

[11] John MJ, Anandjiwala RD. Recent developments in chemical modification and characterization of natural fiber-reinforced composites. Polym Composite 2008;29(2):188207.

[12] Bledzki AK, Gassan J. Composites reinforced with cellulose based fibres. Prog Polym Sci $1999 ; 24(2): 221-274$.

[13] Ahmed KS, Vijayaraangan S, Naidu ACB. Elastic properties, notched strength and fracture criteria in untreated woven jute-glass fabric reinforced polyester hybrid composites. Mater Design 2007;28(8):2287-2294.

[14] Munder F, Hempel H. Mechanical and thermal properties of bast fibers compared with tropical fibers. Mol Cryst Liq Cryst 2006;448:197-209.

[15] Varma DS, Varma M, Varma IK. Coir fibres, Part I: effect of physical and chemical treatments on properties. Text Res J 1984;54(12):827-832.

[16] Silva GG, De Souza DA, Machado JC, Hourston DJ. Mechanical and thermal characterization of native brazilian coir fiber. J Appl Polym Sci 2000;76(7):1197-1206.

[17] Rahman MM. Surface treatment of coir (Cocos nucifera) fibers and its influence on the fibers' physico-mechanical properties. Compose Sci Technol 2007;67(11-12):2369-2376. 